\title{
TÉCNICA COMBINADA DE CLAREAMENTO EM DENTE TRATADO ENDODONTICAMENTE APÓS TRAUMATISMO: ESTUDO DE CASO
}

\author{
COMBINATION OF WHITENING TECHNIQUES OF TOOTH \\ ENDODONTICALLY TREATED AFTER TRAUMA. CASE REPORT
}

\author{
Bibiana Moreira Carvalho* \\ Álvaro Gruendling**
}

\section{RESUMO}

Objetivo: O objetivo deste trabalho é relatar um caso de combinação de técnicas de clareamento em dente, após traumatismo alvéolo-dentário e tratamento endodôntico, avaliando o sucesso da combinação das técnicas de clareamento mediata e imediata. Materiais e método: Foi realizado o clareamento do dente 11, com pasta à base de perborato de sódio e peróxido de hidrogênio, aplicada no interior da câmara pulpar pela técnica mediata. A técnica imediata foi executada utilizando-se o Peróxido de Hidrogênio a 35\% em três aplicações sucessivas por 15 minutos. Isso em cinco sessões sucessivas e, em cada uma delas, era feito o registro da cor para verificar o grau de clareamento após cada sessão. Resultados: Após cinco sessões observou-se dificuldade para atingir o grau de clareamento desejado, pois esse resultado pode variar de acordo com as características de cada paciente. A coloração desejada somente foi atingida após restauração e polimento do dente em questão. Conclusão: Apesar da dificuldade em obter o tom claro do elemento dentário, as técnicas de clareamento interno mediata e imediata mostram serem boas alternativas para o tratamento de dentes escurecidos, pois não exigem desgaste de estrutura dental sadia, sendo, portanto, técnicas conservadoras.

Descritores: Clareamento dental · Estética dentária

\section{ABSTRACT}

Objective: The objective of this study is to report a case of internal and external whitening after trauma and endodontic treatment, assessing the success of the combination of whitening techniques mediate and immediate. Materials and methods: We performed whitening tooth 11, with the base paste of sodium perborate and hydrogen peroxide, applied within the pulp chamber by mediated technique. The immediate technique was performed using Hydrogen Peroxide $35 \%$ in three successive applications for 15 minutes. This in five successive sessions, and in each of them was made the registration of color to check the degree of whitening after each session. Results: After five sessions there was difficulty in achieving the desired degree of whitening because the results may vary depending on the characteristics of each patient. The desired color was achieved only after restoration and polishing the tooth in question. Conclusion: Despite the difficulty in getting a clear tone tooth, techniques mediate and immediate internal bleaching prove to be good alternatives for the treatment of discolored teeth because they don't require wear healthy tooth structure, therefore they are conservative techniques.

Descriptors: Tooth Bleaching • Esthetics, dental

\footnotetext{
* Universidade de Santa Cruz do Sul. Departamento de Enfermagem e Odontologia. Santa Cruz do Sul, RS, Brasil. Acadêmica do curso de Odontologia da Universidade de Santa Cruz do Sul. bib1310@hotmail.com

** Universidade de Santa Cruz do Sul. Departamento de Enfermagem e Odontologia. Santa Cruz do Sul, RS, Brasil. Prof. Mestre do Departamento de Enfermagem e Odontologia da Universidade de Santa Cruz do Sul. alvarogruendling@viavale.com.br
} 
CARVALHO BM

GRUENDLING $A$

TÉCNICA COMBINADA DE CLAREAMENTO EM DENTE TRATADO ENDODONTI CAMENTE APÓS TRAUMATISMO: ESTUDO DE CASO

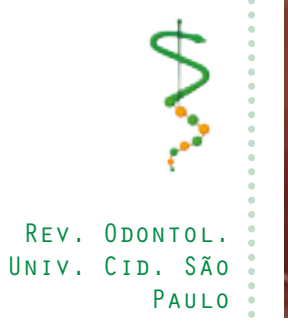

2017; 29(3): 289-99, SET-DEZ

\section{N T RO DUÇÃO}

A estética dos dentes anteriores é uma das principais solicitações dos pacientes, que procuram os consultórios odontológicos. O desejo de um sorriso harmonioso e dentes mais brancos tornam os procedimentos clareadores, em dentes desvitalizados, uma boa alternativa de tratamento, considerando-se o mínimo desgaste da estrutura dental e o baixo custo ${ }^{1}$. Da mesma forma, o conhecimento sobre as técnicas de clareamento está cada vez mais difundido e os pacientes estão buscando alternativas estéticas para dentes que escureceram por traumatismo e tratamento endodôntico. Os resultados podem variar de acordo com cada caso clínico, dependendo das características individuais de cada paciente ${ }^{2}$.

As técnicas para clareamento interno de dentes desvitalizados que apresentam escurecimento da coroa são minimamente invasivas e, por isso, são consideradas boas alternativas para o tratamento estético. Existem algumas limitações nas indicações desse tratamento, que devem ser conhecidas pelo Cirurgião-dentista com o objetivo de fazer um correto plano de tratamento ${ }^{3}$.

Para resolver o problema do escurecimento da coroa dentária existem diversas alternativas, sendo uma delas o clarea-

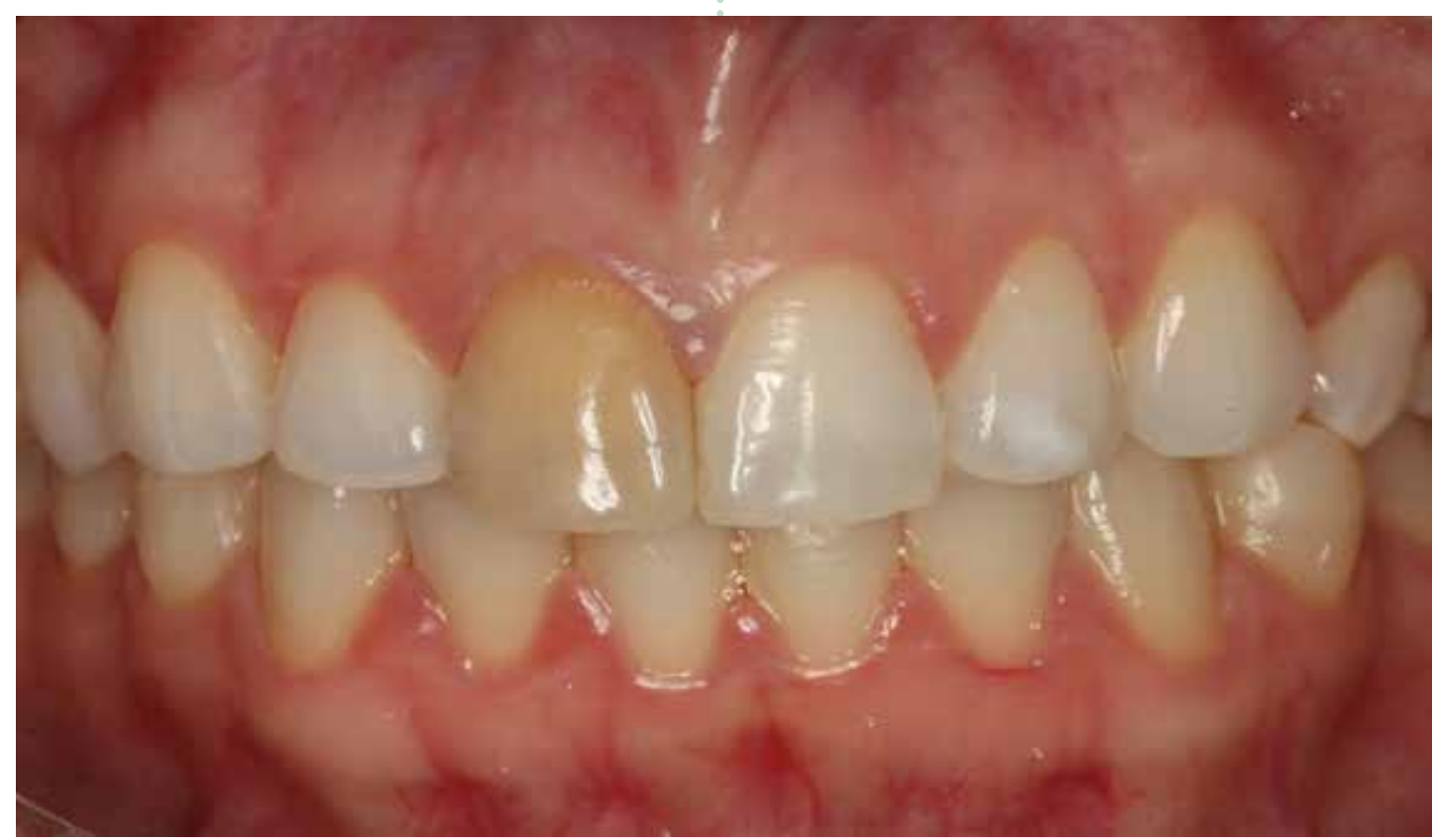

Figura 1. Fonte: Acervo de imagens Prof. Me. Ă/varo Gruendling. mento interno para dentes tratados endodonticamente. Para poder propor um plano de tratamento adequado para o paciente, é preciso ter conhecimento sobre as substâncias clareadoras disponíveis no mercado e ter o domínio das técnicas que poderão levar a resultados mais satisfatórios.

Assim sendo, estão disponíveis ao Cirurgião-dentista diversos materiais clareadores e técnicas diferentes para se alcançar o clareamento dos dentes, tornando a escolha mais difícil de ser feita pelo profissional. A Odontologia atual está preocupada com a conservação das estruturas dentárias e, por isso, as técnicas menos invasivas merecem ser estudadas e ampliados os conhecimentos sobre elas ${ }^{4}$.

Considerando-se alguns estudos da literatura, o clareamento interno é o tratamento mais indicado para casos de escurecimento da coroa dental em dentes que sofreram trauma e, posteriormente, tratamento endodôntico. Especialmente quando estes apresentam-se com integridade das cristas marginais e coroa clínica sem, ou com pouco, material restaurador. Acredita-se que a combinação das técnicas de clareamento mediato e imediato irá obter um resultado ainda mais satisfatório. Assim, o objetivo deste trabalho é relatar um caso de clareamento interno pós-traumatismo alvéolo-dentário e trata- 


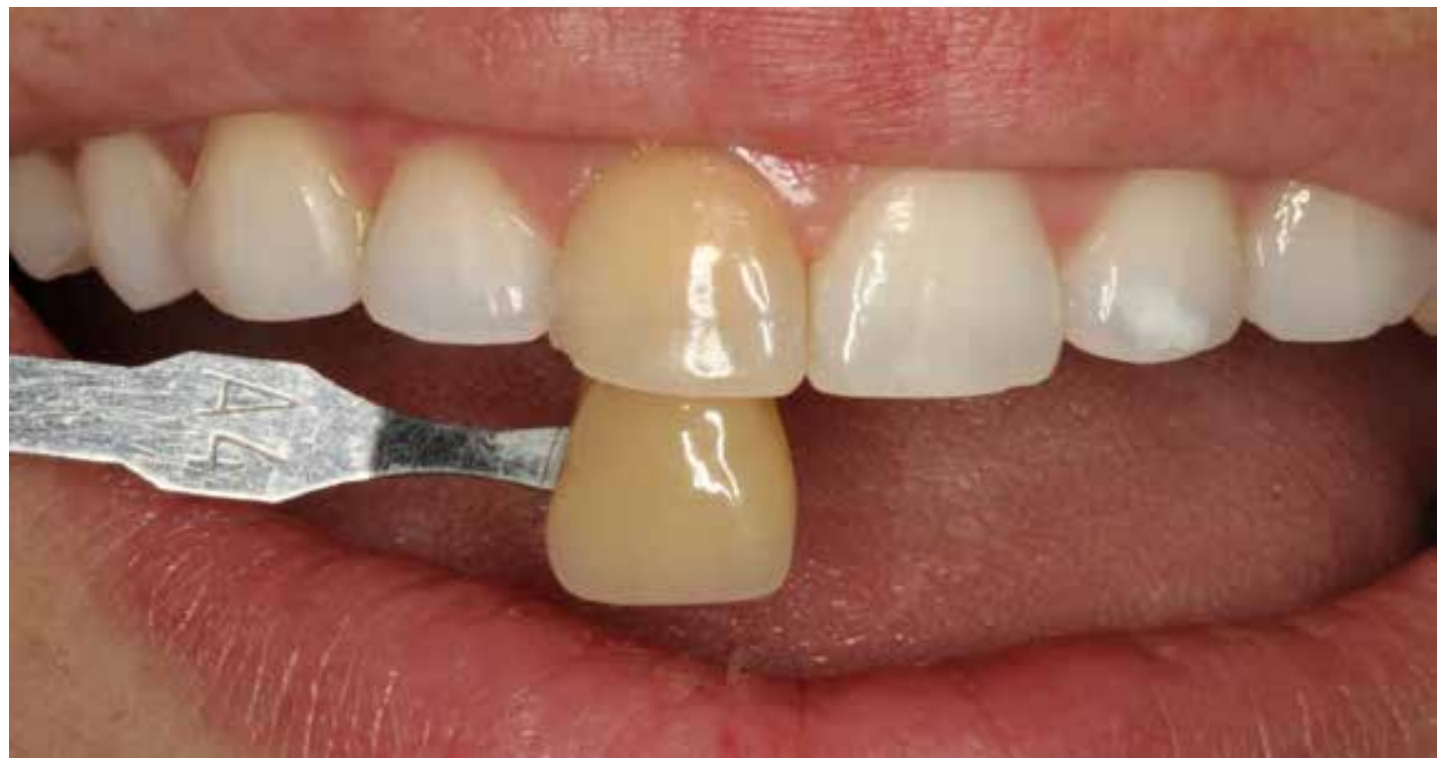

Figura 2. Fonte: Acervo de imagens Prof. Me. Álvaro Gruendling.

mento endodôntico, avaliando o sucesso da combinação das técnicas imediata e mediata.

\section{RELATO DO CASO}

Paciente do gênero feminino, 23 anos de idade, leucoderma, procurou a clínica de Odontologia da Universidade de Santa Cruz do Sul - UNISC, tendo como queixa principal a insatisfação com a estética do sorriso devido ao escurecimento do dente 11. Ao se realizar o exame físico foi identificado que a coroa do dente 11 apresentava-se com escurecimento. Para compreender a etiologia do escurecimento, foram feitas algumas perguntas à paciente, que relatou que há 5 anos sofreu um acidente no qual ocorreu traumatismo do tipo concussão desse dente. O dente traumatizado teve necrose pulpar e o tratamento endodôntico foi realizado. Após cerca de um 1 ano e meio, a paciente percebeu que o dente estava escurecendo gradativamente. A possível causa desse escurecimento, considerando as informações passadas pela paciente durante a anamnese, foi o trauma seguido de hemorragia pulpar. Durante o exame físico foi observado que as cristas marginais do dente se apresentavam íntegras com restauração somente na face palatina, por onde foi realizado o acesso à câmara pulpar para a realização da endodontia. A radiografia periapical do dente 11 mostrou que a obturação do canal estava correta e sem lesão peria- pical. Após se realizarem a anamnese, o exame físico, os exames complementares e fotografias, foi possível traçar o plano de tratamento, no qual foi escolhido o clareamento interno do dente 11 como mais indicado para tal caso clínico.

Na primeira sessão, após se constatar que o dente apresentava cor A4, foi realizada a abertura coronária na face palatina com ponta diamantada 1014 (KG-Sorense - Cotia, SP). Nesse momento foi observado que havia um grande desgaste de dentina na parede vestibular, provavelmente ocorrido durante a realização da endodontia. Foi feita a desobturação de $3 \mathrm{~mm}$ do material obturador, com brocas Gattes e Largo. O isolamento absoluto foi realizado posteriormente à desobturação do canal para realização do selamento cervical com cimento de ionômero de vidro (Vidrion R - SSWHITE $囚$, São Paulo, $\mathrm{SP})$. Esse passo é muito importante para vedar corretamente a entrada do conduto radicular, impedindo o extravasamento de material clareador para dentro do conduto radicular. O condicionamento da estrutura dentária com ácido fosfórico 37\% (Angelus ${ }^{\circ}$ - Londrina, PR) foi realizado com o objetivo de remover a smear layer. $\mathrm{O}$ tratamento iniciou-se pela técnica mediata com aplicação da pasta clareadora Claridex Endo (Biodinâmica - Ibiporã, PR) à base de perborato de sódio e peróxido de hidrogênio; foi inserida no interior da câmara pulpar, pela técnica de Walking
CARVALHO BM

GRUENDLING A

TÉCNICA COMBINADA

DE CLAREAMENTO

EM DENTE TRATADO

ENDODONTICAMENTE

APÓS TRAUMATISMO:

ESTUDO DE CASO
REV, ODONTOL.

UnIV. CID. SÃo

PAULO

2017; 29(3):

289-99, SET-DEZ 
CARVALHO BM

GRUENDLING A

TÉCNICA COMBINADA DE CLAREAMENTO EM DENTE TRATADO ENDODONTI CAMENTE APÓS TRAUMATISMO: ESTUDO DE CASO

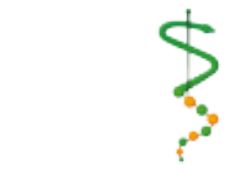

REV, ODONTOL UNIV, CID, SÃO PAULO

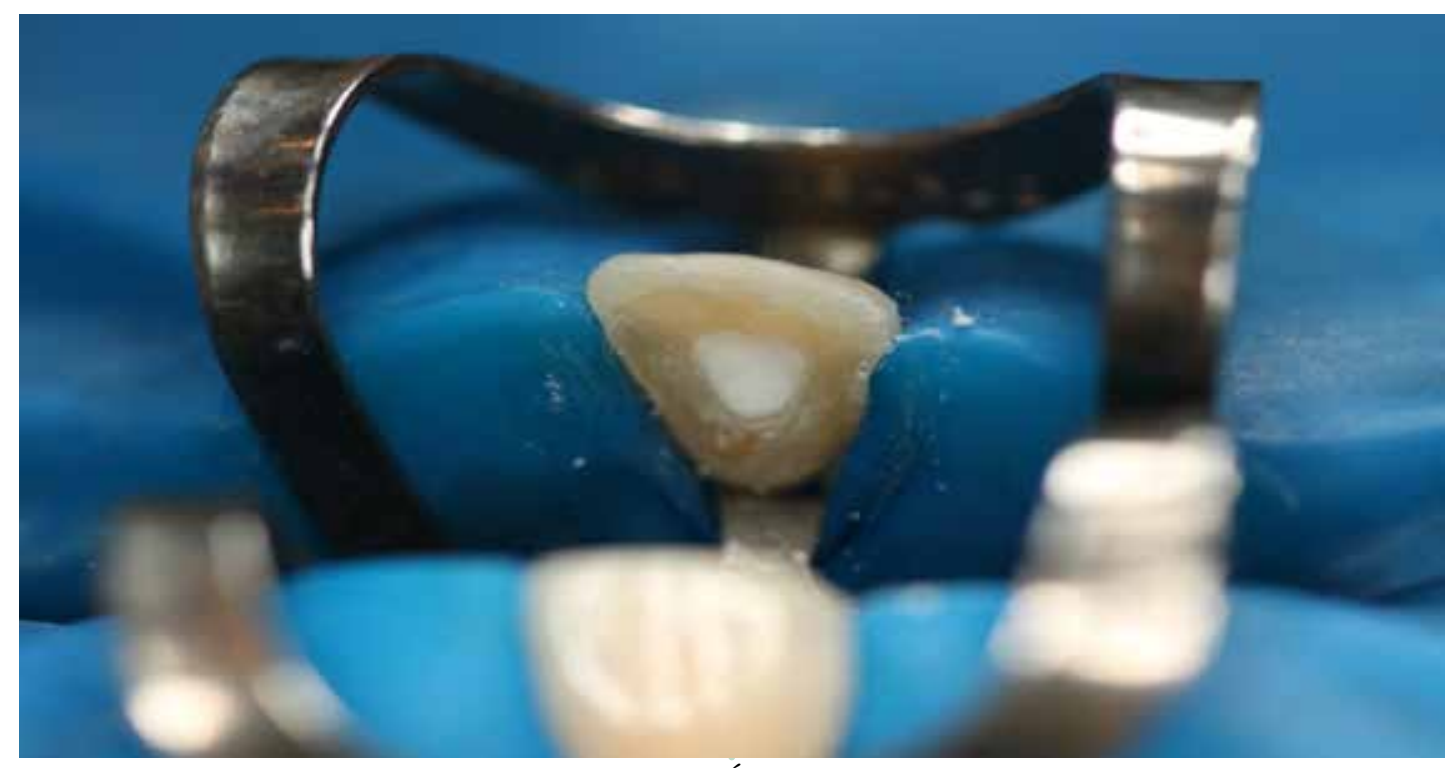

Figura 3. Fonte: Acervo de imagens Prof. Me. Á/varo Gruendling.

Bleach, seguindo as instruções do fabricante e foi realizado selamento coronário com resina composta cor B2 (CHARISMA®, Heraeus Kulzer - Alemanha), com o objetivo de obter uma restauração mais resistente, considerando-se que a expansão dos gases gerados pelas substâncias clareadoras exercem forças capazes de expulsar o selamento da coroa.

Na segunda sessão, foi feito registro da cor, observando-se que houve pouca mudança, de A4 para A3.

Então foi realizada a combinação das técnicas imediata e mediata, na tentativa de se obter um efeito mais rápido e efetivo do clareamento. A técnica imediata foi realizada com Peróxido de Hidrogênio 35\% Whiteness HPmaxx 35 (FGM - Joinville, SC), em duas aplicações do material dentro e fora da câmara pulpar por 15 minutos. O Claridex Endo foi introduzido mais uma vez na câmara pulpar e permaneceu por mais uma semana. Esse procedimento foi repetido por mais três sessões.

Ao se realizar o exame clínico, percebeu-se que a cor ainda não estava de acordo com o desejo da paciente. Aplicou-se mais uma sessão do clareamento imediato com Whiteness HPMmaxx 35 (FGM Joinville, SC), três aplicações sucessivas

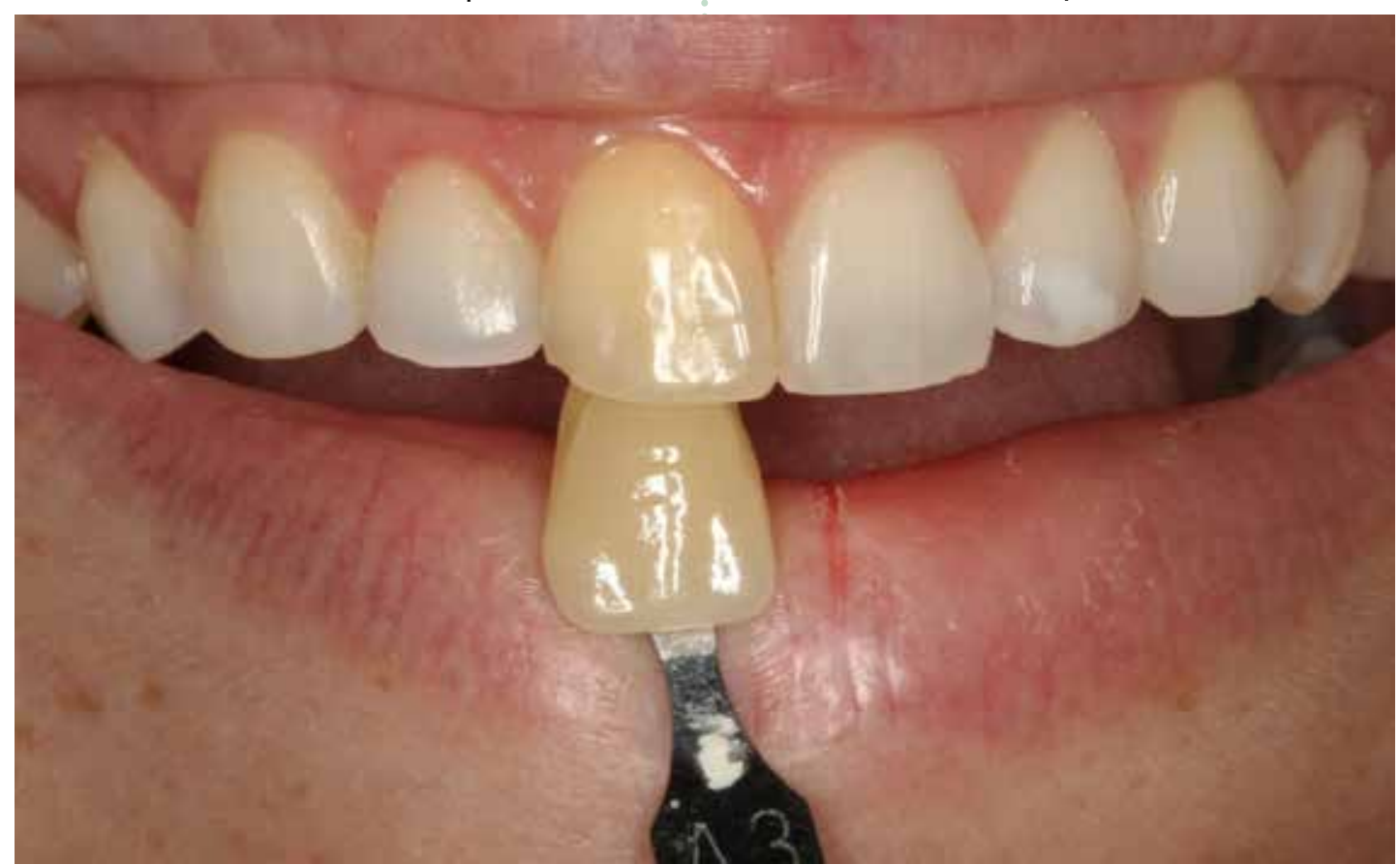

Figura 4. Fonte: Acervo de imagens Prof. Me. Álvaro Gruendling. 


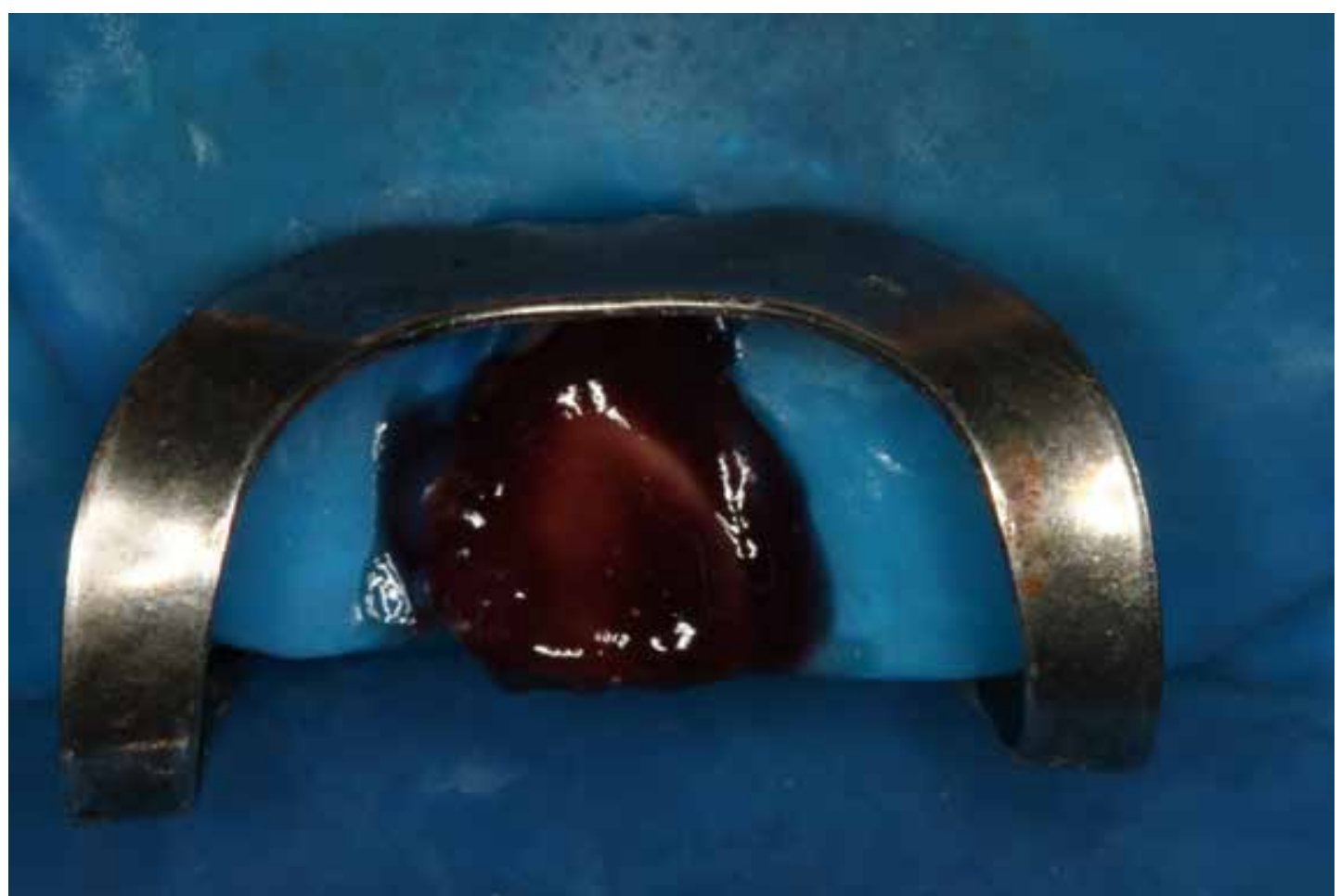

Figura 5. Fonte: Acervo de imagens Prof. Me. Álvaro Gruendling.

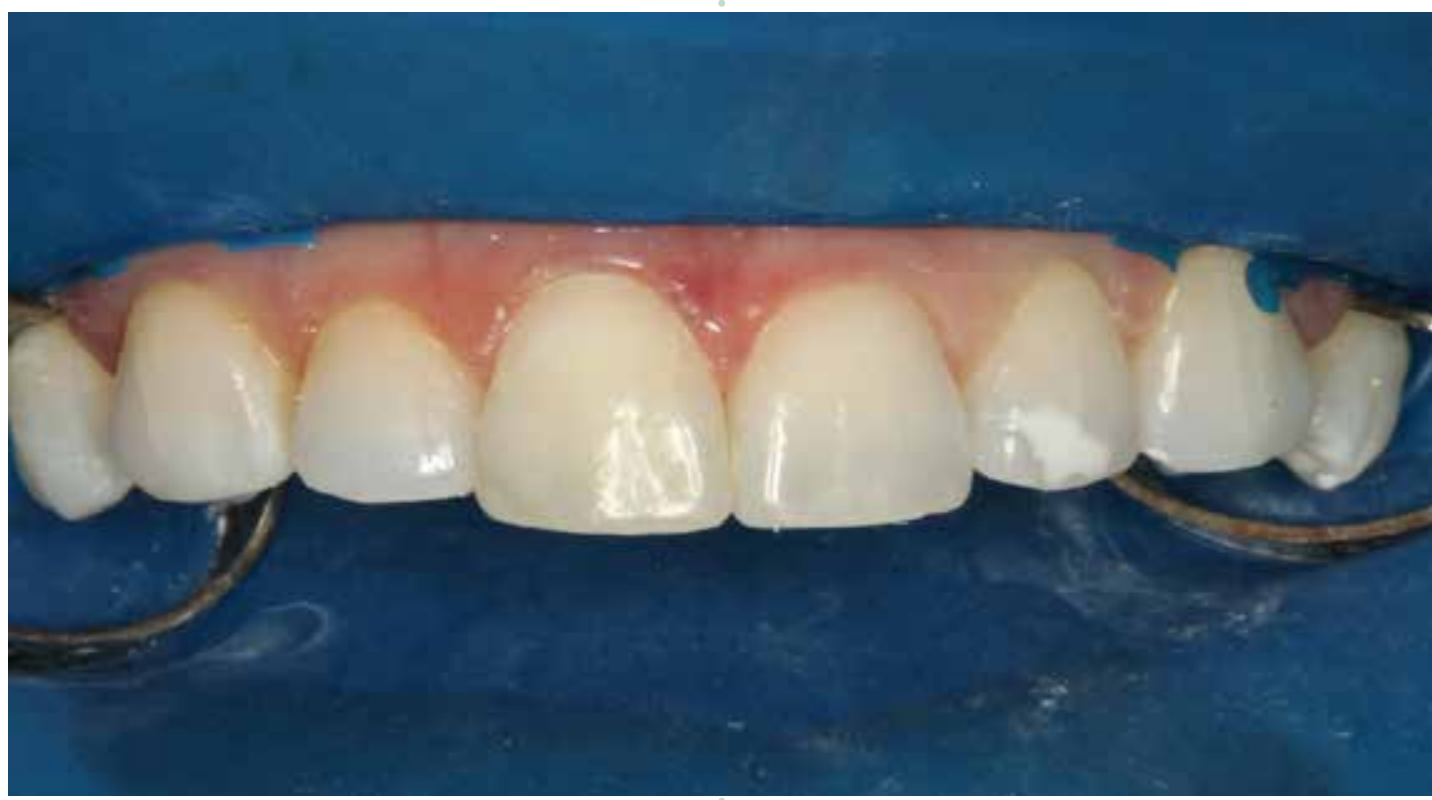

Figura 6. Fonte: Acervo de imagens Prof. Me. Á/varo Gruendling.

por 15 minutos. Após esse procedimento, foi introduzida na câmara pulpar pasta de hidróxido de cálcio (Callen - SSWHITE®, São Paulo, SP). Essa pasta permaneceu no dente por 8 dias com a finalidade de neutralizar o $\mathrm{pH}$ do meio e permitir total liberação do oxigênio, que causa a diminuição da resistência de união da resina à estrutura dentária.

Ao final do tratamento clareador, foi realizada a restauração definitiva, utilizando-se resina composta de corpo $\mathrm{W}$ para dentes clareados, resina $\mathrm{A} 1$ dentina e B1 esmalte (Z350-3M- ESPE, São Paulo, SP). A utilização dessas cores de resina favoreceu a estética do dente, devido ao alto valor da resina $\mathrm{W}$ que proporcionou um fundo claro ao dente, alcançando a cor final A1.

Uma semana depois da restauração foi realizada uma sessão de polimento visando aumentar o brilho desse dente. Utilizaram-se discos de lixa (TDV-, pasta diamantada com disco de feltro (TDV),
CARVALHO BM

GRUENDLING A

TÉCNICA COMBINADA

DE CLAREAMENTO

EM DENTE TRATADO

ENDODONTI CAMENTE

APÓS TRAUMATISMO:

ESTUDO DE CASO

$\therefore 293$.

REV, ODONTOL.

UNIV. CID. SÃO

PAULO

2017; 29(3):

289-99, SET-DEZ 
CARVALHO BM

GRUENDLING A

TÉCNICA COMBINADA DE CLAREAMENTO EM DENTE TRATADO ENDODONTICAMENTE APÓS TRAUMATISMO: ESTUDO DE CASO
REV, ODONTOL . UNIV, CID. SÃO

PAULO

$2017 ; 29(3)$ : $289-99$, SET-DEZ

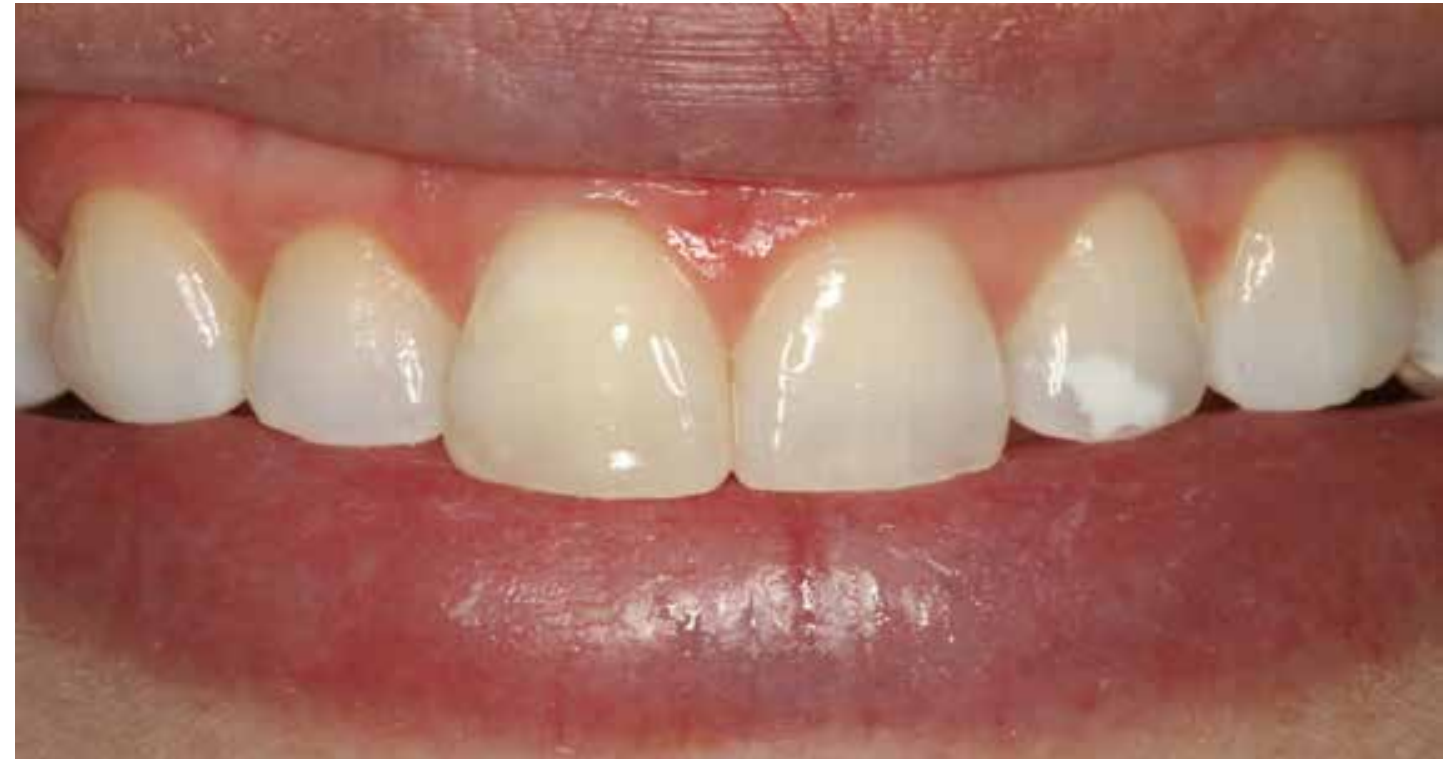

Figura 7. Fonte: Acervo de imagens Prof. Me. Á/varo Gruendling.

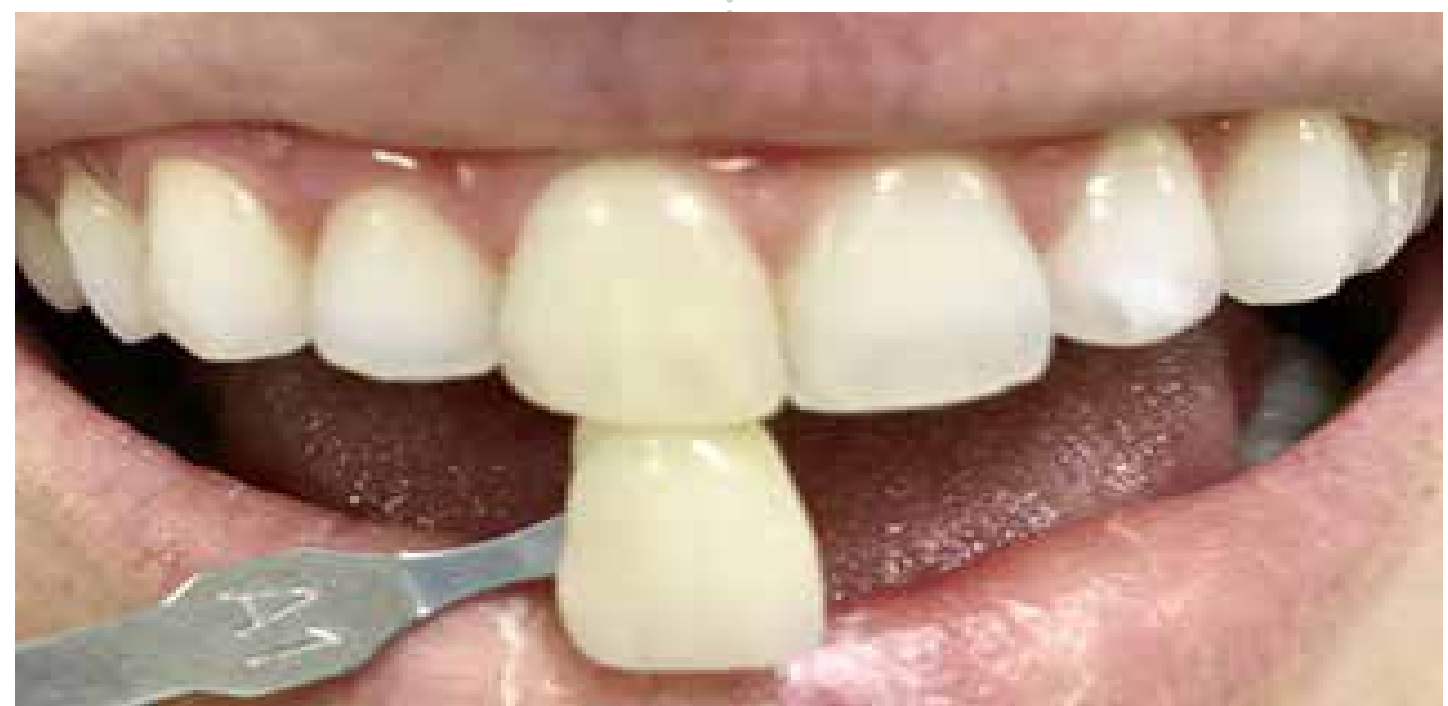

Figura 8. Fonte: Acervo de imagens Prof. Me. Álvaro Gruendling.

e escova Jiffy Brush (Ultradent-São Paulo). Após o polimento foram alcançados a cor e o brilho desejados ao elemento dentário. Para complementar os efeitos do clareamento realizado no consultório, foi aplicado Peróxido de Carbamida $16 \%$ (Whiteness Perfect - FGM - Joinville, SC) com moldeira, apenas no dente 11 , pela técnica de clareamento caseira por mais duas semanas.

\section{RESULTADOS}

Observou-se dificuldade em atingir o grau de clareamento desejado, mesmo realizando todos os procedimentos corretamente, e os produtos sendo manipulados como indicado nas instruções do fabricante. Foram necessárias cinco sessões do clareamento pela técnica mista, para que se conseguisse um tom claro, porém não igual aos dentes adjacentes. A restauração em resina de corpo $\mathrm{W}$, devido ao seu alto valor, foi determinante para alcançar o tom claro A1. A sessão de polimento/acabamento proporcionou brilho e luminosidade, deixando o sorriso mais harmonioso.

\section{I SCUSSÃO}

O escurecimento dental pode ocorrer por fatores considerados intrínsecos e extrínsecos. Os fatores intrínsecos estão relacionados, em grande parte, ao uso de medicamentos como a tetraciclina durante a amelogênese, pigmentos de materiais utilizados em tratamentos endodônticos 
ou pigmentos que são depositados após hemorragia pulpar por traumatismo ou pulpectomias. Os fatores extrínsecos estão associados a uso de tabaco, consumo de alimentos com corante como sucos e refrigerantes ${ }^{5}$.

A hemorragia pulpar causada por traumatismo é uma das causas mais comuns para o escurecimento dental. Ela ocorre pela ruptura dos vasos sanguíneos permitindo a entrada de hemoglobina dentro dos túbulos dentinários. Em paciente jovem os autores destacam que o poder de penetração é ainda maior, devido aos túbulos dentinários serem mais amplos. Após a entrada da hemoglobina nos túbulos dentinários, ocorre a oxidação da mesma que se transforma em sulfeto de ferro, originando a coloração escurecida ao elemento dentário ${ }^{6}$. Por isso, identificar a etiologia do escurecimento dental, considerando a natureza, composição e origem da mancha, é fundamental para ter sucesso no tratamento clareador. Um esquema da decomposição da hemácia seria:

Hemácia (hemólise)-> hemoglobina -> sulfeto de hidrogênio + ferro -> sulfeto de ferro (coloração)-> anidrido sulfuroso (odor) ${ }^{6}$.

No caso relatado, a causa do escurecimento foi a hemorragia pulpar, por isso as técnicas de clareamento foram corretamente indicadas.

Para realizar o clareamento interno é imprescindível que o caso esteja corretamente indicado, tendo o dente as características necessárias para que se obtenha o sucesso desejado. Essas características são cristas marginais íntegras, mínimo de restaurações possíveis, tratamento endodôntico bem realizado e sem lesão apical. É importante que seja observado se há presença de trincas no elemento dentário que possam fazer comunicação com a câmara pulpar, permitindo o extravasamento do material clareador. Isso fará com que o material não desempenhe sua função clareadora e também poderá causar danos aos tecidos moles ${ }^{7}$. Como identificado no exame clínico, o dente em questão apresentava todos esses requisitos, concordando com os autores. Conhecer a etiologia da alteração da cor do elemento dentário também corrobora com os efeitos do tra- tamento a ser proposto ${ }^{8}$. O trauma seguido do tratamento endodôntico, quando causa do escurecimento dentário, indica a realização do clareamento interno, visto que alterações de cor oriundas de materiais restauradores têm um prognóstico não favorável quanto ao clareamento ${ }^{7}$.

Quanto à escolha da técnica a ser utilizada, foi realizada uma revisão de literatura com o objetivo de relatar os procedimentos e técnicas empregadas para clarear dentes não-vitais. A técnica de Walking Bleach é eficaz quando realizada com os agentes clareadores Perborato de Sódio com água destilada ou Peróxido de Hidrogênio ${ }^{9}$. Diversos autores concordam que ambas as misturas apresentam resultados satisfatórios, porém outros autores defendem que utilizar o Perborato de Sódio com Peróxido de Hidrogênio apresenta resultados mais rápidos e satisfatórios do que com água destilada ${ }^{10-12}$. A preferência pela técnica de Walking Bleach se dá pelo maior sucesso que esta apresenta, quando comparada à técnica termocatalítica, que está associada com o aumento do índice de reabsorção cervical externa pelo aquecimento do Peróxido de Hidrogênio. A técnica utilizada neste caso clínico foi eleita após a pesquisa e constatação de que esses resultados estão de acordo com outros estudos com os mesmos objeti$\operatorname{vos}^{11,12}$. Os resultados deste estudo são semelhantes a outros presentes na literatura, sugerindo a eficácia desta técnica ${ }^{4-13}$.

Embora o clareamento interno em dentes tratados endodonticamente seja muito utilizado pelos profissionais de Odontologia, ele pode causar efeitos indesejáveis, como a reabsorção cervical externa. Por esse motivo é necessário realizar o tampão cervical, vedando a entrada dos canais e impedindo a passagem da substância para o periodonto ${ }^{14}$. A efetividade do vedamento de diversos materiais, como o $\mathrm{Ci}$ mento de lonômero de Vidro, Cimento de fosfato de zinco e o Cimento Resinoso, foi testada em estudos e todos apresentaram falhas no vedamento cervical ${ }^{15,16}$. Esses estudos demonstraram que nenhum dos materiais proporcionou perfeito vedamento, ou seja, é necessário o acompanhamento radiográfico para observar as ocorrências de reabsorções cervicais externas ${ }^{17}$.
CARVALHO BM

GRUENDLING A

TÉCNICA COMBINADA

DE CLAREAMENTO

EM DENTE TRATADO ENDODONTICAMENTE APÓS TRAUMATISMO: ESTUDO DE CASO

\section{5}

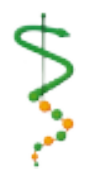

REV, ODONTOL.

UNIV. CID, São PAULO

2017; $29(3)$ :

$289-99$, SET - DEZ 
CARVALHO BM

GRUENDLING A

TÉCNICA COMBINADA DE CLAREAMENTO EM DENTE TRATADO ENDODONTI CAMENTE APÓS TRAUMATISMO: ESTUDO DE CASO

\section{6}

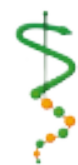

REV, ODONTOL

UNIV. CID, SÃO

PAULO

2017; $29(3):$

289-99, SET-DEZ
I SSN 1983-5183

Pelos motivos largamente descritos na literatura, foi utilizado o Perborato de Sódio associado ao Peróxido de Hidrogênio dentro da câmara pulpar no período de uma semana em trocas sucessivas ${ }^{18,19}$. Associado a esta técnica realizou-se a aplicação do Peróxido de Hidrogênio a 35\% como tentativa de potencializar os efeitos do clareamento interno. Foram necessárias cinco sessões para atingir resultados satisfatórios na coloração do elemento dentário, corroborando com um relato de dois casos clínicos descritos na literatura, no qual houve a necessidade de realizar cinco sessões até que a cor desejada fosse conquistada ${ }^{20}$. Autores concordam que a eficácia das técnicas de clareamento interno, estão relacionadas à etiologia do escurecimento, profundidade, localização e tempo do mesmo, bem como do produto utilizado ${ }^{7-21}$. Neste presente relato, esse fato também foi observado.

O uso do Peróxido de Carbamida no clareamento dental caseiro, utilizando moldeira, apresenta bons resultados nas concentrações $10 \%$ e $16 \%$. O gel na concentração $16 \%$ apresenta resultados mais rápidos e está indicado em casos em que a pigmentação é mais severa . Alguns estudos relatam eficácia da utilização do Peróxido de Carbamida em dentes desvitalizados, indicando a utilização desse agente clareador também após o clareamento interno, especialmente em casos onde somente o clareamento interno não atendeu às expectativas desejadas, semeIhante ao caso apresentado neste estudo.

Embora o clareamento dental seja um procedimento que apresenta resultados satisfatórios e, portanto, muito solicitado pelos pacientes nos consultórios, os resultados podem ser diferentes em longo prazo, existindo a possibilidade de recidiva de cor ${ }^{22}$. Em um estudo realizado em 1988, foi identificada recidiva de cor em $50 \%$ dos casos dos 58 dentes despolpados, 8 anos após o tratamento clareador ${ }^{23}$. A recidiva pode ocorrer, inicialmente, pela difusão de pigmentos e pela infiltração de microorganismos entre a restauração e a superfície dentinária ${ }^{8}$. Alguns estudos presentes na literatura relatam casos de recidiva de cor em 3 a 5 anos após o tratamento. Entretanto, em casos de reci- diva, o tratamento pode ser repetido ou realizados outros tratamentos restauradores ou protéticos ${ }^{20}$. Essas alternativas estão disponíveis ao Cirurgião-dentista que deve sempre considerar os riscos de reabsorção cervical externa, não submetendo o órgão dentário escurecido a procedimentos desnecessários. Por esse motivo, o tratamento da recidiva pode ser efetuado tão somente com o uso de Peróxido de Carbamida, utilizado em moldeiras, como feito na finalização deste caso clínico ${ }^{21}$.

Apesar de os números de recidiva de cor serem consideráveis, a escolha pelo clareamento interno ainda é a mais vantajosa quando comparada a outros tratamentos, por ser minimamente invasiva. A confecção de facetas, em resina ou em porcelana, pode ser realizada em casos em que o dente apresente grandes restaurações e manchamentos e/ou em casos em que o clareamento interno não consiga atingir a expectativa estética do paciente ${ }^{24}$. Portanto, é importante ressaltar para o paciente, no início do tratamento, que esse procedimento é uma tentativa de alcançar uma cor favorável ao dente, sem que seja realizado o desgaste de estrutura dentária sadia. Porém, os resultados não são previsíveis e dependem de diversos fatores.

A restauração definitiva deve ser realizada após a espera de 7-14 dias da colocação de pasta de Hidróxido de Cálcio na câmara pulpar. Os autores concordam com a literatura, que esta deve ser muito bem realizada, para evitar a infiltração de bactérias, bem como, de pigmentos extrínsecos que podem levar ao escurecimento do elemento dentário ${ }^{14}$. Por esse motivo deve-se respeitar esse período com o objetivo de eliminar o oxigênio presente, resultante do procedimento clareador, que interfere na adesão da resina à estrutura dentária. Em um estudo clínico, todos os dentes que apresentavam restaurações insatisfatórias tiveram recidiva de cor imediatamente após o término do tratamento. Isso demonstra que essa recidiva ocorre principalmente pela infiltração de partículas extrínsecas, oriundas de alimentos com corantes, e não pela redução química dos produtos de oxidação dos agentes clareadores $^{25}$. 
A dificuldade para atingir a cor desejada do elemento dentário encontrada neste estudo demonstra que a expectativa do paciente quanto ao resultado do tratamento é um fator de extrema importância a ser considerado ${ }^{26}$. É fundamental alertar sobre os riscos de não se conseguir chegar ao tom ideal ou igual aos dentes adjacentes, pois depende de diversos fatores e não apenas da técnica aplicada ou dos conhecimentos do Cirurgião-dentista.

Os resultados podem variar de acordo com as características particulares de cada paciente. O profissional não tem como prever nem controlar qual será a resposta de cada tratamento perante a individualidade de cada dente. Isso demonstra a importância de relatar claramente ao paciente, antes de começar o tratamento, que não é possível garantir sucesso no caso e, assim, evitar maiores frustrações, nunca criando expectativas que poderão não ser atingidas. Os casos de recidiva podem necessitar retratamento, mas este sempre deve ser bem considerado, devido ao risco de reabsorções externas.

\section{CONCLUSÃO}

Trata-se de um procedimento minimamente invasivo, sem desgaste de estrutura dental sadia, o que torna este tratamento uma das primeiras opções para os profissionais. O resultado desta técnica não é previsível, uma vez que depende de diversos fatores que não dependem do profissional.

Os agentes clareadores mais utilizados para clareamento interno são o Perborato de Sódio associado com Peróxido de Hidrogênio ou água destilada, na técnica mediata. O Peróxido de Hidrogênio a $35 \%$ pode ser aplicado em consultório com a técnica imediata, aumentando o nível de sucesso do tratamento.

Os resultados clínicos permitiram concluir que a combinação das técnicas mediata e imediata de clareamento apresenta bons resultados e, portanto, podem ser consideradas uma alternativa de tratamento eficaz. Se o clareamento não apresentar os resultados desejados, ainda é possível partir para as técnicas menos conservadoras como restaurações, facetas ou laminados, considerando que este tratamento não impossibilita o Cirurgião-dentista de realizar os demais procedimentos posteriormente. Devemos sempre considerar que a execução de uma perfeita técnica restauradora pode aprimorar o resultado final a ser obtido, especialmente quando o resultado da técnica clareadora não for o esperado.

É importante ressaltar que, neste caso clínico, o excesso de desgaste da estrutura dentária, causado pelo tratamento endodôntico, trouxe limitações ao tratamento clareador, porém favoreceu a técnica restauradora que deixou transparecer a cor da resina composta que apresentava um croma semelhante ao do dente em questão.

Este caso clínico contribuiu para ampliar os conhecimentos sobre as técnicas mediata e imediata de clareamento dental, bem como os conhecimentos a respeito dos agentes clareadores disponíveis no mercado e suas indicações.
CARVALHO BM

GRUENDLING A

TÉCNICA COMBINADA

DE CLAREAMENTO

EM DENTE TRATADO

ENDODONTI CAMENTE

APÓS TRAUMATISMO:

estudo de caso

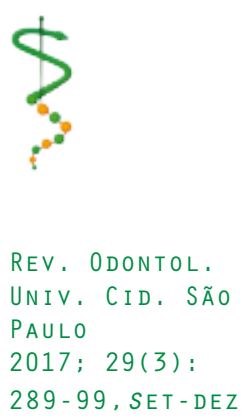


CARVALHO BM

GRUENDLING A

TÉCNICA COMBINADA DE CLAREAMENTO EM DENTE TRATADO ENDODONTI CAMENTE APÓS TRAUMATISMO: ESTUDO DE CASO

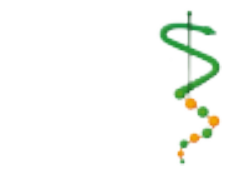

REV, ODONTOL UNIV, CID, SÃO PAULO 2017; 29(3): 289-99, SET-DEZ

\section{REFERÊNCIAS}

1. Marson FC, Sensi LG, Araujo FdO, Monteiro Junior S, Araujo E. Avaliação clínica do clareamento dental pela técnica caseira. R Dental Press Estét. 2005;2(4):84-90.

2. Campagnoli KR, Junior NS. Clareamento de dentes desvitalizados: técnica LED com peróxido de hidrogênio. Rev Clín Pesq Odontol. 2008;4(2):10712.

3. Martins JD, Bastos LC, Gaglianone LA, Bezerra RB, de Morais PMR. Diferentes alternativas de clareamento para dentes escurecidos tratados endodonticamente. Revista de Ciências Médicas e Biológicas. 2010;8(2):213-8.

4. Rodrigues E, Panzarini SR, Pedrini D. Clareamento dentário após traumatismo dento-alveolar. RGO. 2006;54(4):379-93.

5. Bortolatto J, Corsi CE, Presoto CD, Cioffi SS, Oliveira Júnior OBd. Clareamento interno em dentes despolpados como alternativa a procedimentos invasivos: relato de caso. Revista de Odontologia da Universidade Cidade de São Paulo. 2012;24(2):142-52.

6. Busato A, Barbosa A, Bueno M, Baldisera R. Dentística: restaurações de dentes anteriores. São Paulo: Artes Médicas; 1997.

7. Monteiro Junior S, Andrada MACd, Vieira LCC, Baratieri LN. Clareamento dental. São Paulo: Santos; 1993.

8. Watts A, Addy M. Tooth discolouration and staining: a review of the literature. British dental journal. 2001;190(6):309-16.

9. Attin T, Paque F, Ajam F, Lennon AM. Review of the current status of tooth whitening with the walking bleach technique. International endodontic journal. 2003;36(5):313-29.
10. Boaventura JMC, Roberto AR, Lima JPMd, Padovani GC, Brisighello LC, Andrade MFd. Clareamento para dentes despolpados: revisão de literatura e considerações. Revista de Odontologia da Universidade Cidade de São Paulo. 2012;24(2):114-22.

11. Erhardt MCG, Shinohara MS, Pimenta LA. Clareamento dental interno. RGO (Porto Alegre). 2003;51(1):23-9.

12. Lucena M, Mantovani M, Fracalossi C, Silva G. Clareamento interno em dentes desvitalizados com a técnica Walking Bleach - Relato de caso. Revista Uninigá Review 2015;24(1):339.

13. Costa AP. Comparação de dois tipos de tampão cervical durante clareamento dental interno. Rev Assoc Paul Cir Dent. 2010;64(5):391-4.

14. Palo R. Penetração de peróxido da câmara pulpar para a superfície radicular externa após clareamento interno [Dissertação de Mestrado]. São José dos Campos2005.

15. Cardoso RM, Júnior PCM, Gomes GL, Souza FB, Silva CHV. Avaliação radiográfica de tampões cervicais no clareamento endógeno. RGO. 2006;54(3):280-83.

16. Gomes $\mathrm{MEdO}$, Ribeiro $\mathrm{BCl}$, Yoshinari GH, Pereira KFS, Gonçalves JdB, Candido MSM. Análise da eficácia de diferentes materiais utilizados como barreira cervical em clareamento endógeno. RGO. 2008;56(3):275-9.

17. Vasconsellos WA, Assis BRP, Albuquerque RdC. Avaliação da capacidade de vedamento da região cervical por materiais usados na confecção do tampão durante o clareamento dental endógeno. Publicatio UEPG: Ciências Biológicas e da Saúde. 2000;6(1):2942. 
18. Sampaio MD, Freitas APd, Araújo RPCd. Análise espectrofotométrica do clareamento dental interno. RGORevista Gaúcha de Odontologia. 2010;58(3):363-8.

19. Lim MY, Lum SO, Poh RS, Lee GP, Lim KC. An in vitro comparison of the bleaching efficacy of 35\% carbamide peroxide with established intracoronal bleaching agents. International endodontic journal. 2004;37(7):483-8.

20. Dietschi D, Rossier S, Krejci I. In vitro colorimetric evaluation of the efficacy of various bleaching methods and products. Quintessence international (Berlin, Germany : 1985). 2006;37(7):51526.

21. Farias VB, Hõfling RTB, Carvalho ASd, Bussadori SK, Bassanta AD. Clareamento dental caseiro e clareamento dental interno. RGO 2003;51(4):28992.

22. Agnihotry A, Gill KS, Singhal D, Fedorowicz $Z$, Dash $S$, Pedrazzi V. A comparison of the bleaching effectiveness of chlorine dioxide and hydrogen peroxide on dental composite. Brazilian dental journal. 2014;25(6):524-7.
23. Friedman S, Rotstein I, Libfeld H, Stabholz A, Heling I. Incidence of external root resorption and esthetic results in 58 bleached pulpless teeth. Endodontics \& dental traumatology. 1988;4(1):23-6.

24. Cardoso PC, Almeida Decurcio R, Pacheco AFR, Monteiro Júnior LJE, Lima PLA, Silva RF. Facetas diretas de resina composta e clareamento dental: estratégias para dentes escurecidos. ROBRAC - Revista Odontológica do Brasil Central. 2012;20(55):341-47.

25. Abbott P, Heah SY. Internal bleaching of teeth: an analysis of 255 teeth. Australian dental journal. 2009;54(4):32633.

26. Silva FM, Nacano LG, Pizi ECG. Avaliação clínica de dois sistemas de clareamento dental. ROBRAC - Revista Odontológica do Brasil Central. 2012;21(57).

Recebido em 15/05/2017

Aceito em 14/08/2017
CARVALHO BM

GRUENDLING A

TÉCNICA COMBINADA

DE CLAREAMENTO

EM DENTE TRATADO

ENDODONTICAMENTE

APÓS TRAUMATISMO:

ESTUDO DE CASO

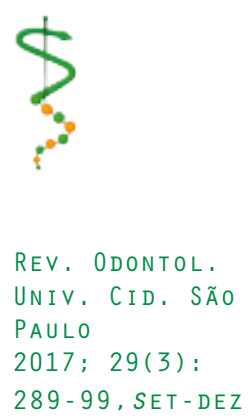

